\title{
The effect of simulated heat-shock and daily temperature fluctuations on seed germination of four species from fire- prone ecosystems
}

\author{
Talita Zupo'*, M. Jaime Baeza ${ }^{2,3}$ and Alessandra Fidelis ${ }^{1}$
}

Received: May 29, 2016

Accepted: August 10, 2016

\begin{abstract}
Seed germination in many species from fire-prone ecosystems may be triggered by heat shock and/or temperature fluctuation, and how species respond to such fire-related cues is important to understand post-fire regeneration strategies. Thus, we tested how heat shock and daily temperature fluctuations affect the germination of four species from fire-prone ecosystems; two from the Cerrado and two from the Mediterranean Basin. Seeds of all four species were subjected to four treatments: Fire (F), temperature fluctuations (TF), fire+temperature fluctuations (F+TF) and control (C). After treatments, seeds were put to germinate for 60 days at $25^{\circ} \mathrm{C}$ (dark). Responses differed according to species and native ecosystem. Germination percentage for the Cerrado species did not increase with any of the treatments, while germination of one Mediterranean species increased with all treatments and the other only with treatments that included fire. Although the Cerrado species did not respond to the treatments used in this study, their seeds survived the exposure to heat shock, which suggests they possess tolerance to fire. Fire frequency in the Cerrado is higher than that in Mediterranean ecosystems, thus traits related to fire-resistance would be more advantageous than traits related to post-fire recruitment, which are widespread among Mediterranean species.
\end{abstract}

Keywords: Cerrado, Mediterranean Basin, mean germination time, physical dormancy, post-fire germination

Fire is a natural disturbance present in many ecosystems worldwide where plant species can persist by resprouting, recruiting from seeds, or use both strategies (Bond \& Midgley 2001; Pausas et al. 2004; Bond \& Keeley 2005). Consequently, in fire-prone ecosystems, plant species can show different seed germination strategies that optimize plant survival in face of recurrent fires, where germination may be triggered by different mechanisms, such as heat shocks, temperature fluctuations and smoke (Williams et al. 2005; Moreira et al. 2010; Santana et al. 2010; 2013; Moreira \& Pausas 2012).

Intense short-term heating effects caused by fire have been reported to enhance germination in several species of fire-prone ecosystems, mainly in hard-seeded species

\footnotetext{
${ }^{1}$ Departamento de Botânica, Instituto de Biociências, Universidade Estadual Paulista, Av. 24A, 1515, 13506-900, Rio Claro, SP, Brazil

${ }^{2}$ Fundación Centro de Estudios Ambientales del Mediterráneo, C/ Charles Darwin, 14. 46980, Paterna, Valencia, Spain

${ }^{3}$ Departamento de Ecologia, Universidad de Alicante, Ap. 99. E-03080. Alicante, Spain

* Corresponding author: talita.zupo@gmail.com
} 
where high temperatures may break physical dormancy enabling germination (Williams et al. 2003; Reyes \& Trabaud 2009; Moreira et al. 2010; Moreira \& Pausas 2012). Other studies have found no evidence that heat shocks effectively trigger germination in species with both permeable and impermeable seeds (Luna et al. 2007; Dayamba et al. 2010; Jaureguiberry \& Diaz 2015; Le Stradic et al. 2015; Fichino et al. 2016; Fidelis et al. 2016). Although some species from fire-prone ecosystems showed to be unaffected by high temperatures produced during fire, their seeds survived the exposure to high temperatures, and could be considered as fire-resistant (Luna et al. 2007; Jaureguiberry \& Diaz 2015; Le Stradic et al. 2015; Fichino et al. 2016; Fidelis et al. 2016).

After fire, gaps open within the vegetation and lead to an increase in the incidence of solar radiation, altering soil temperatures (Auld \& Bradstock 1996; Santana et al. 2013), which results in seeds being exposed to high temperatures (e.g. $50-55^{\circ} \mathrm{C}$ ) and wide temperature fluctuations. Recent studies have indicated that these temperature fluctuations also act as germination cues in hard-seeded species, breaking physical dormancy and enabling germination (Baeza \& Roy 2008; Santana et al. 2010; 2013; Jaganathan 2015). Moreover, in non-dormant seeds, daily temperature fluctuations may affect the rate of germination (Musso et al. 2015; Le Stradic et al. 2015). However, some hardseeded species require higher temperature thresholds for dormancy release, and physical dormancy is broken with temperatures reached only with fire (Moreira \& Pausas 2012; Ooi et al. 2014). Ooi et al. (2014) suggested that species whose physical dormancy is broken with lower temperature thresholds, e.g. temperatures reached in vegetation gaps, have facultative pyrogenic dormancy, while those species that need higher temperatures, reached only with fire, have obligate pyrogenic dormancy.

Considering that responses of seeds to fire-related cues can be different according to species and the fireprone ecosystems where they occur, the aim of our study was to evaluate whether high temperatures caused by fire and/or the daily temperature fluctuations would affect the germination and the mean germination time of four species present in fire-prone ecosystems.

We selected species (three Fabaceae and one Cistaceae) that are very common in the fire-prone ecosystems they occur. Mimosa leiocephala Benth. and Bauhinia dumosa Benth. are two shrub species (resprouters) found in Cerrado campo sujo - a grassland type with a continuous herbaceous layer and scattered shrubs. Ulex parviflorus Pourr. and Cistus albidus L. are shrub species (seeders) found along the Mediterranean coasts of Southwestern Europe (Tutin et al. 1964-1980).

Fires in Cerrado are surface fires of relatively low intensity that rapidly consume the herbaceous biomass (Miranda et al. 2002) and can occur every 3-4 years (Coutinho 1982). During fires, temperatures at soil surface can range from $74^{\circ} \mathrm{C}$ to $768^{\circ} \mathrm{C}$ in open savanna-like Cerrado (Miranda et al.
1993; Pivello et al. 2010), while maximum temperatures $1 \mathrm{~cm}$ belowground usually increase up to around $50^{\circ} \mathrm{C}$ (Miranda et al. 1993), but can occasionally reach over $80^{\circ} \mathrm{C}$ (T Zupo unpubl. res.). Post-fire temperatures registered in vegetation gaps ranged from 16 to $50^{\circ} \mathrm{C}$ at soil surface (A Fidelis unpubl. res.). Mediterranean fires are crown fires, which consume canopy biomass of shrub species, and are considered high intensity fires that occur once in several decades (Keeley et al. 2011). Fire temperatures in such shrublands can reach up to $400^{\circ} \mathrm{C}$ at soil surface (Baeza et al. 2002) and between 80 and $99^{\circ} \mathrm{C} 1 \mathrm{~cm}$ belowground, with maximum post-fire temperature in vegetation gaps between 49 and $53^{\circ} \mathrm{C}$ (Santana et al. 2013).

Seeds from the Cerrado species were collected in July and October 2013 in a campo sujo area located at the Serra do Tombador Nature Reserve, Goiás, Central Brazil. They were stored in glass recipients at $5^{\circ} \mathrm{C}$ until the beginning of the experiment in December 2013. Seeds of U. parviflorus and C. albidus were collected in July and November 2013 in a shrubland with Pinus halepensis Mill. located near Alicante (Spain), and stored in plastic bags at controlled temperatures $\left(20^{\circ} \mathrm{C}\right)$, until the beginning of the experiment in December 2013. Seeds of all species have orthodox seed storage behavior thus the viability is not affected by storage under low temperatures (Royal Botanic Gardens Kew 2016).

Seeds of all species were subjected to four different treatments prior to germination tests: Fire $(\mathrm{F})$, temperature fluctuations $(\mathrm{TF})$, fire + temperature fluctuations $(\mathrm{F}+\mathrm{TF})$ and a control (C). For each species, we used four replicates containing 25 seeds in each treatment. We replicated the experiment three times in order to obtain temporal replications since we only had one alternating temperature incubator ( 25 seeds $\mathrm{x} 4$ replicates $\mathrm{x} 4$ treatments $\mathrm{x} 3$ temporal replications $=1200$ seeds/species). Thus, the experiment is considered a block design with each temporal replicate being a block.

In the $\mathrm{F}$ treatment, seeds were put in a regular incubator with an initial temperature of $25^{\circ} \mathrm{C}$, rising up to $80^{\circ} \mathrm{C}$ in ten minutes and then continuously decreasing its temperature back to $25^{\circ} \mathrm{C}$ in one hour, simulating the passage of fire $1 \mathrm{~cm}$ belowground (Fig. 1A). The TF treatment consisted of exposing the seeds to daily cycles of alternating temperatures $\left(15^{\circ} \mathrm{C}\right.$ to $50^{\circ} \mathrm{C}-$ Fig. $\left.1 \mathrm{~B}\right)$ during 30 days in an alternating temperature incubator (Binder KB E5.1) to simulate the daily temperature fluctuation that occurs in vegetation gaps, both in post-fire conditions and in natural conditions during the summers in the Mediterranean Basin and the dry seasons in the Cerrado. For treatment F + TF, both treatments were combined with seeds being first exposed to the high temperatures simulating the passage of fire and subsequently being exposed to the alternating temperatures for 30 days. Finally, Control seeds were not exposed to any of the treatments mentioned above, and seeds were stored at a constant temperature of $20^{\circ} \mathrm{C}$ until put to germinate. This procedure was applied for each temporal replicate. 

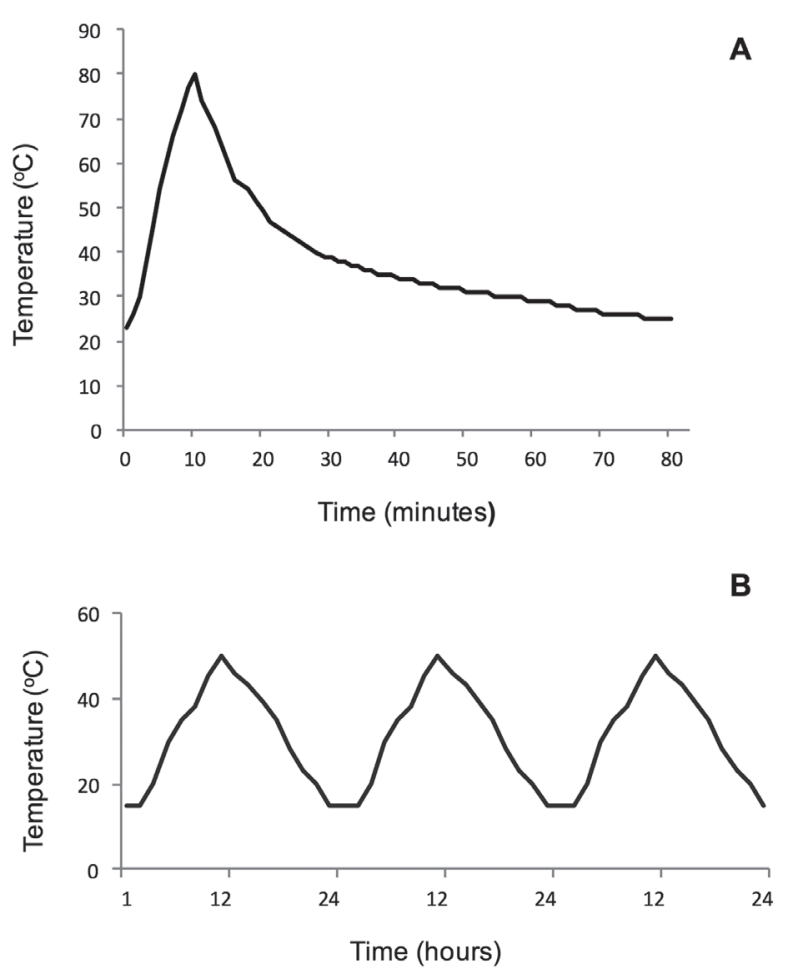

Figure 1. Temperature curves that simulate (A) the passage of fire at $1 \mathrm{~cm}$ deep soil, $\mathrm{F}$ treatment and (B) daily temperature fluctuations after the removal of vegetation, TF treatment.

Seeds were then placed in Petri dishes with one layer of filter paper saturated with distillated water, and put in germination chambers at $25^{\circ} \mathrm{C}$ (dark). Seed germination was recorded every two days for 60 days and germination was determined by radicle emergence (Bewley et al. 2013). Mean germination time was calculated according to Ranal \& Santana (2006). Viability of non-germinated seeds was analyzed at the end of each experiment by means of the Tetrazolium test at $1 \%$ solution (AOSA 2005).

Assuming a block design with each temporal replicate being a block, one-way analysis of variance applied to randomization tests (Euclidean distance between sampling units, 10000 iterations) were carried out to evaluate differences in germination percentage and mean germination time between the different treatments (fixed factor) for each species. All statistical analyses were performed using MULTIV (Pillar 2008).

Seeds of Bauhinia dumosa showed high germination percentages (> 80\%) in all treatments, including the control, whereas seeds of Mimosa leiocephala showed low germination $(\leq 30 \%)$ in all treatments. B. dumosa showed lower germination percentage in treatments where fluctuating temperatures were involved $(84.2 \pm 4.5 \%$ and $86.7 \pm 6.1 \%$ in $\mathrm{F}+\mathrm{TF}$ and TF treatments, respectively) in relation to both $\mathrm{F}$ treatment $(97.3 \pm 2.8 \%$, both $\mathrm{p} \leq 0.001)$ and to control $(98.2 \pm 1.6 \%$, both $\mathrm{p}<0.001$; Fig. $2 \mathrm{~A})$. For this species, however, $\mathrm{F}$ treatment did not differ from the control ( $\mathrm{p}=0.13$; Fig. 2A). Germination percentage of $M$. leiocephala was not affected by F, F+TF and TF treatments (p>0.05; Fig. 2B).

While Ulex parviflorus responded to all treatments, Cistus albidus responded only to $\mathrm{F}$ treatments. Germination percentage of $U$. parviflorus was over $65 \%$ in all treatments, except for the control, where germination percentage was $43.7 \pm 3.7 \%$ (Fig. 2C). Even though there were no significant differences between $\mathrm{F}, \mathrm{F}+\mathrm{TF}$ and $\mathrm{TF}$ treatments, they showed greater germination percentage in relation to the control (all $\mathrm{p} \leq 0.001$; Fig. 2C). Cistus albidus showed higher germination in $\mathrm{F}$ treatment in relation to all other treatments $(23.8 \pm 18 \%$, all $\mathrm{p} \leq 0.001$ ), where germination percentage was $<5 \%$ (Fig. 2D).

Seed viability (germinated + stained seeds) remained high after treatments for all species ( $>70 \%)$. Even though $M$. leiocephala and C. albidus showed low germination percentages, non-germinated seeds were viable.

Treatments with temperature fluctuations increased the mean germination time of $B$. dumosa (32.4 \pm 5.1 days for $\mathrm{F}+\mathrm{TF}$ and $31.2 \pm 7.6$ days for $\mathrm{TF})$ in relation to $F$ treatment $(16.4 \pm 2.2$ days, both $\mathrm{p} \leq 0.001)$ and to the control $(12.5 \pm 1.4$ days, both $\mathrm{p}<0.001$; Fig. 3A). For M. leiocephala, mean germination time was greater in TF treatments $(16.4 \pm 2.8$ days $)$ in relation to treatments that involved high temperatures simulating the passage of fire (F, $12.9 \pm 5.2$ days, $\mathrm{p}=0.048$ and $\mathrm{F}+\mathrm{TF}, 13.4 \pm 2.6$ days, $\mathrm{p}=0.01)$, but did not differ from the control (14.5 \pm 1.4 days, $\mathrm{p}>0.05$; Fig. 3B). On the other hand, mean germination time of $U$. parviflorus seeds was not affected by F, F+TF and TF treatments ( $p>0.05$, Fig. 3C). Mean germination time of C. albidus was not calculated given that few seeds germinated in the control, $\mathrm{F}+\mathrm{TF}$ and TF treatments.

Several studies have reported an increase in germination percentage after heat shocks for many species of fire-prone ecosystems, especially for those with physically dormant seeds (Williams et al. 2003; Reyes \& Trabaud 2009; Moreira et al. 2010; Moreira \& Pausas 2012). In our study, germination responses to heat shocks were variable: heat shocks did not enhance germination of Mimosa leiocephala and Bauhinia dumosa, but effectively broke dormancy of Ulex parviflorus and Cistus albidus, enabling germination.

Seeds of $M$. leiocephala had low germination percentages $(\leq 30 \%)$ in all treatments with seeds maintaining its viability at the end of the experiment (>90\% viable), confirming the presence of physical dormancy and indicating no fire-dependency regarding dormancy break. Hard-seeded species might have different heat tolerance and different temperature thresholds for dormancy release (Ooi et al. 2014). M. leiocephala did not have their dormancy broken by the heat shocks of $80^{\circ} \mathrm{C}$ used in this experiment, but they did not die when exposed to this temperature, confirming previous studies that seeds of Cerrado are not stimulated by fire, but might be tolerant (Ribeiro \& Borghetti 2014; Fichino et al. 2016). However, seeds of U. parviflorus and $C$. albidus, known to be physically dormant (Baeza 

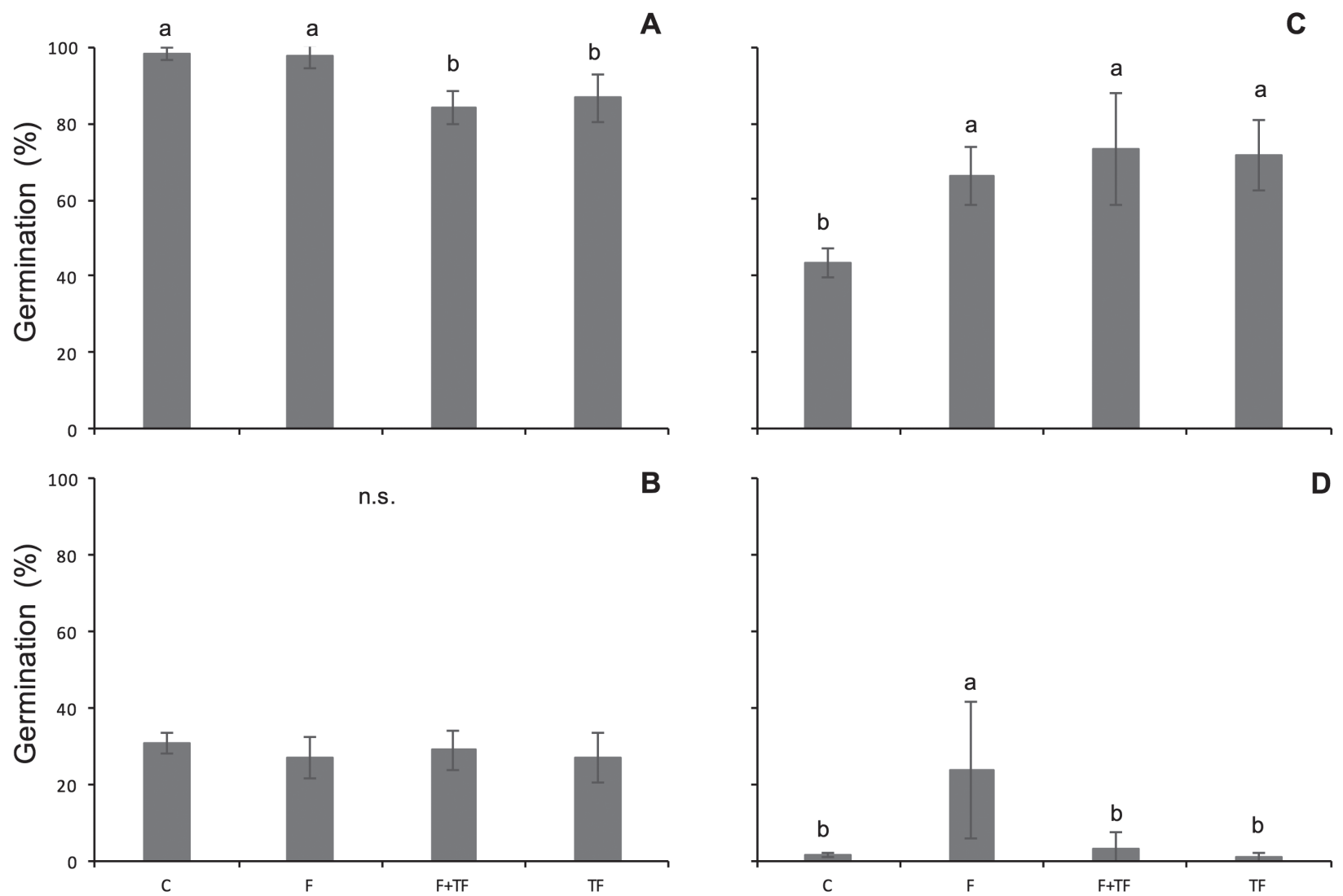

Figure 2. Germination percentage (mean \pm SD) for A) Bauhinia dumosa, B) Mimosa leiocephala, C) Ulex parviflorus and D) Cistus albidus subjected to the treatments $\mathrm{C}=\mathrm{Control} ; \mathrm{F}=$ Fire; $\mathrm{F}+\mathrm{TF}=$ fire followed by temperature fluctuation and $\mathrm{TF}=$ temperature fluctuation. Different letters mean significant differences, $p \leq 0.05$.

\& Vallejo 2006; Moreira et al. 2010), showed an increase in germination after being exposed to such temperature, indicating that the heat shocks were effective in releasing their seeds from dormancy, as has been reported for many hard-seeded species of fire-prone ecosystems (Williams et al. 2003; 2005; Reyes \& Trabaud 2009; Moreira et al. 2010; Moreira \& Pausas 2012; Ooi et al. 2014).

Such as $M$. leiocephala, other hard-seeded species of subtropical grasslands (Fidelis et al. 2016) and also from Cerrado (Fichino et al. 2016) did not have their dormancy broken by one-minute heat shocks ranging between 60 and $200^{\circ} \mathrm{C}$, suggesting that seeds are resistant to high temperatures and some other mechanism, such as fluctuating temperatures, might be involved in releasing seeds of these species from dormancy. Nonetheless, treatments involving fluctuating temperatures in this study were also unable to break dormancy for $M$. leiocephala, and the mechanism for dormancy release remains unclear. Additional combinations of temperature and time of exposure or exposing seeds to temperature fluctuations for longer periods of time might be effective in breaking dormancy. On the other hand, temperature fluctuations broke physical dormancy of seeds of U. parviflorus, suggesting that this species might have lower temperature thresholds for dormancy release (Ooi et al. 2014). Given that the germination of U. parviflorus is stimulated by both fire and fluctuating temperatures, $U$. parviflorus could be considered as having facultative pyrogenic dormancy release, as proposed by Ooi et al. (2014), where germination occurs both with temperatures related to fire and to seasonal temperature changes (Santana et al. 2013; Jaganathan 2015).

Alternatively, $B$. dumosa showed high germination percentages $(>80 \%)$ in all treatments, indicating that seeds from this species are water permeable and do not have dormancy. Cerrado woody species with permeable seed coats (Ribeiro et al. 2013; Ribeiro \& Borghetti 2014), and herbaceous species with permeable seeds of campo rupestre (Le Stradic et al. 2015) and campo sujo (Fichino et al. 2016) were also unaffected by heat shocks of temperatures > $80^{\circ} \mathrm{C}$. On the other hand, fluctuating temperatures led to a decrease in germination percentage of $B$. dumosa and an increase in mean germination time, which might mean that seeds from this species recognize high temperature amplitudes as an unfavorable environmental condition adopting a strategy of not betting all of its seeds at once. This could also be explained by dispersal timing (Salazar et al. 2011), given that this species has no dormancy and shed its seeds at the end of the dry season (personal observation), 




Figure 3. Germination time (mean \pm SD) for A) Bauhinia dumosa, B) Mimosa leiocephala and C) Ulex parviflorus subjected to the treatments $\mathrm{C}=$ Control; $\mathrm{F}=$ Fire; $\mathrm{F}+\mathrm{TF}=$ fire followed by temperature fluctuation and $\mathrm{TF}=$ temperature fluctuation. Different letters mean significant differences, $p \leq 0.05$.

allowing them to germinate with the onset of the rainy season that follows. Such response is not a direct effect of fire, but could be seen as an indirect effect given that the amount of gaps increases after the passage of fire. Furthermore, since many natural fires in Cerrado occur at the end of the dry season (Ramos-Neto \& Pivello 2000), during the dispersion time of this species, being able to resist high temperatures during fire events should be important for germination during the rainy season.
Even though we found no direct response to fire-related cues in the germination of M. leiocephala and B. dumosa, seeds of both species tolerated the heat shocks they were exposed to, which could be seen as an adaptation to frequent burning (Overbeck et al. 2006). Moreover, both M. leiocephala and B. dumosa are resprouters (T Zupo unpubl. res.), suggesting that resprouting may be the dominant mechanism for persistence after fire in these species, as in many Cerrado species (Simon et al. 2009; Simon \& Pennington 2012). On the other hand, germination percentage of U. parviflorus and C. albidus seeds were enhanced with $\mathrm{F}$ treatments, suggesting that temperatures reached with the passage of fire are effective in breaking seed dormancy and enabling germination in these species, which is particularly important for obligate seeder species, whose regenerating strategy after fire relays exclusively on seed germination and establishment (Bond \& Midgley 2001; Pausas et al. 2004), as is the case for both these species (Baeza \& Vallejo 2006; Santana et al. 2010).

This study has shown that germination response to fire-related cues may vary according to species and to the fire-prone ecosystems where they occur, which could be due to different fire regimes. Fire frequency in Cerrado is higher than in Mediterranean ecosystems, and thus, traits related to fire-resistance would be more advantageous in such ecosystems than traits related to post-fire recruitment, which are widespread among Mediterranean species. Moreover, Mediterranean species may present germination traits for both heat requirements and temperature fluctuations, enabling regeneration by seeds in post-fire environments, but also in fire free intervals.

\section{Acknowledgments}

We thank E.P. Ferrándiz and M.N. Rissi for assistance with lab activities. We thank Conselho Nacional de Desenvolvimento Científico e Tecnológico - CNPq (455183/2014-7), the Coordenação de Aperfeiçoamento de Pessoal de Nível Superior (CAPES/DGU11623/13-6), and the Fundação de Amparo à Pesquisa do Estado de São Paulo (FAPESP 2015/06743-0) for financial support. M.J.B. acknowledges the support from the program FORESTERRA ERA-Net (Medwildfirelab, PCIN-2013-140-C04-03) and AF receives a productivity grant from $\mathrm{CNPq}$ (306170/2015-9).

\section{References}

AOSA - Association of official seed analysts. 2005. Tetrazolium testing handbook. Ithaca, AOSA.

Auld TD, Bradstock RA. 1996. Soil temperatures after the passage of a fire: do they influence the germination of buried seeds? Australian Journal of Ecology 21: 106-109.

Baeza MJ, Raventos J, Escarre A. 2002. Ulex parviflorus germination after experimental burning: effects of temperature and soil depth. In: Trabaud L, Prodon R. (eds.) Fire and biological processes. Leiden, Backhuys Publishers. p. 83-92. 


\section{The effect of simulated heat-shock and daily temperature fluctuations on seed germination of four species from fire-prone ecosystems}

Baeza MJ, Roy J. 2008. Germination of an oblígate seeder (Ulex parviflorus) and consequences for wildlife management. Forest Ecology and Management 256: 685-693.

Baeza MJ, Vallejo VR. 2006. Ecological mechanisms involved in dormancy breakage in Ulex parviflorus seeds. Plant Ecology 183: 191-205.

Bewley JD, Bradford K, Hilhorst H, Nonogaki H. 2013. Seeds - Physiology of Development, Germination and Dormancy. 3rd. edn. New York, Springer.

Bond WJ, Keeley JE. 2005. Fire as a global 'herbivore': the ecology and evolution of flammable ecosystems. Trends in Ecology and Evolution 20: 387-394.

Bond WJ, Midgley JJ. 2001. Ecology of sprouting in woody plants: the persistence niche. Trends in Ecology and Evolution 16: 45-51.

Coutinho LM. 1982. Ecological effects of fire in Brazilian Cerrado. In: Huntley BJ, Walker BH. (eds.) Ecology of tropical savannas. Springer Berlin Heidelberg. p. 273-291.

Dayamba SS, Sawadogo L, Tigabo M, et al. 2010. Effects of aqueous smoke solutions and heat on seed germination of herbaceous species of the Sudanian savana-woodland in Burkina Faso. Flora 205: 319-325.

Fichino BS, Dombroski JRG, Pivello VR, Fidelis A. 2016. Does fire trigger seed germination in the neotropical savannas? Experimental test with six Cerrado species. Biotropica 48: 181-187.

Fidelis A, Daibes LF, Martins AR. 2016. To resist or to germinate? The effect of fire on legume seeds in Brazilian subtropical grasslands. Acta Botanica Brasilica 30: 147-151.

Janagathan GK. 2015. Are wildfires an adapted ecological cue breaking physical dormancy in the Mediterranean basin? Seed Science Research 25: $120-126$.

Jaureguiberry P, Diaz S. 2015. Post-burning regeneration of the Chaco seasonally dry forest: germination response of dominant species to experimental heat shock. Oecologia 177: 689-699.

Keeley JE, Pausas JG, Rundel PW, Bond WJ, Bradstock RA. 2011. Fire as an evolutionary pressure shaping plant traits. Trends in Plant Science 16: 406-411.

Le Stradic S, Silveira FAO, Buisson E, Cazelles K, Carvalho V, Fernandes GW. 2015. Diversity of germination strategies and seed dormancy in herbaceous species of campo rupestre grasslands. Austral Ecology 40: 537-546.

Luna B, Moreno JM, Cruz A, Fernández-González F. 2007. Heat-shock and seed germination of a group of Mediterranean plant species growing in a burned area: An approach based on plant functional types. Environmental and Experimental Botany 60: 324-333.

Miranda AC, Miranda HS, Dias IFO, Dias BFS. 1993. Soil and air temperatures during prescribed Cerrado fires in Central Brazil. Journal of Tropical Ecology 9: 313-320.

Miranda HS, Bustamante MMC, Miranda AC. 2002. The fire fator. In Oliveira PS, Marquis RJ. (eds.) The Cerrados of Brazil. New York, Columbia University Press. p. 51-68

Moreira B, Pausas JG. 2012. Tanned or burned: the role of fire in shaping physical seed dormancy. Plos One 7(12): e51523.

Moreira B, Tormo J, Estrelles E, Pausas JG. 2010. Disentangling the role of heat and smoke as germination cues in Mediterranean Basin flora. Annals of Botany 105: 627-635.

Musso C, Miranda HS, Aires SS, Bastos AC, Soares AMVM, Loureiro S. 2015. Simulated post-fire temperature affects germination of native and invasive grasses in Cerrado (Brazilian savanna). Plant Ecology \& Diversity 8: 219-227.
Ooi MKJ, Denham AJ, Santana, VM, Auld TD. 2014. Temperature thresholds of physically dormant seeds and plant functional response to fire: variation among species and relative impact of climate change. Ecology and Evolution 4: 656-671.

Overbeck GE, Müller SC, Pillar VD, Pfadenhauer J. 2006. No heatstimulated germination found in herbaceous species from burned subtropical grassland. Plant Ecology 184: 237-243.

Pausas JG, Bradstock RA, Keith DA, Keeley JE, GCTE Fire Network. 2004. Plant functional traits in relation to fire in crown-fire ecosystems. Ecology 85: 1085-1100.

Pillar VD. 2008. Multiv: multivariate exploratory analysis, randomization testing and bootstrap resampling. Porto Alegre, Universidade Federal do Rio Grande do Sul.

Pivello VR, Oliveras I, Miranda HS, Haridasan M, Sato MN, Meirelles ST. 2010. Effects of fire on soil availability in an open savanna in Central Brazil. Plant Soil 337: 111-123.

Ramos-Neto MB, Pivello VR. 2000. Lighting fires in a Brazilian savanna national park: rethinking management strategies. Environmental Management 26: 675-684

Ranal MA, Santana DG. 2006. How and why to measure the germination process? Revista Brasileira de Botânica 29: 1-11.

Reyes O, Trabaud L. 2009. Germination behaviour of 14 Mediterranean species in relation to fire factors: smoke and heat. Plant Ecology 202: 113-121.

Ribeiro LC, Borghetti F. 2014. Comparative effects of desiccation, heat shock and high temperatures on seed germination of savanna and forest tree species. Austral Ecology 39: 267-278.

Ribeiro LC, Pedrosa M, Borghetti F. 2013. Heat shock effects on seed germination of five Brazilian savanna species. Plant Biology 15: 152-157.

Royal Botanic Gardens Kew. 2016. Seed Information Database (SID). Version 7.1. Available from: http://data.kew.org/sid/. 1 may 2016.

Salazar A, Goldstein G, Franco AC, Miralles-Wilhelm F. 2011. Timing of seed dispersal and dormancy, rather than persistent soil seed-banks, controlling seedling recruitment of woody plants in Neotropical savannas. Seed Science Research 21: 103-116.

Santana VM, Bradstock RA, Ooi MKJ, Denham AJ, Auld TD, Baeza MJ. 2010. Effects of soil temperature regimes after fire on seed dormancy and germination in six Australian Fabaceae species. Australian Journal of Botany 58: 539-545.

Santana VM, Baeza MJ, Blanes MC. 2013. Clarifying the role of fire and daily temperature fluctuations as germination cues for Mediterranean Basin obligate seeders. Annals of Botany 111: 127-134.

Simon MF, Grether R, Queiroz LP, Skema C, Pennington RT, Hughes CE. 2009. Recent assembly of the Cerrado, a neotropical plant diversity hotspot, by in situ evolution of adaptations to fire. PNAS 106: 2035920364.

Simon MF, Pennington T. 2012. Evidence for adaptation to fire regimes in the tropical savannas of the Brazilian Cerrado. International Journal of Plant Science 173: 1-14

Tutin TG, Heywood VH, Burges NA, et al. (eds.). 1964-1980. Flora Europea. Cambridge, Cambridge University Press.

Williams PR, Congdon RA, Grice AC, Clarke PJ. 2003. Fire-related cues break seed dormancy of six legumes of tropical eucalypt savannas in north-eastern Australia. Austral Ecology 28: 507-514.

Williams PR, Congdon RA, Grice AC, Clarke PJ. 2005. Germinable soil seed banks in a tropical savanna: seasonal dynamics and effects of fire. Austral Ecology 30: 79-90. 